\title{
Exhibition development through cross-institutional collaborative design
}

\author{
Eva Insulander and Eva Svärdemo Åberg
}

\section{Introduction}

Over the years the interest in collaboration between different professionals in order to develop knowledge has increased. Many different ways of conducting collaborative design projects have also been recognized by scholars in the field of design research (McKenney \& Reeves, 2019; Wang \& Hannafin, 2005; van den Akker, 1999). Doing collaborative design projects has many benefits and it has also been described in terms of conducting development research. van den Akker (1999) defines some key features of such research and these include collaboration (e.g., participants and researchers working together with a focus on practice development), intervention (developing more or less theory-based solutions for designs), and iteration (conducting repeating cycles of investigation, development, testing, and refinement).

To plan and implement an exhibition is a complex project. In museums it is increasingly common to bring together a cross-departmental team of experts, each of whom is familiar with their own area of knowledge. A curatorial team may consist of a project manager (or curator), educators, discipline specialists, exhibit designers, media producers, as well as carpenters, technicians, and so on. It has also become more common to involve external participants in exhibition projects (Mygind et al., 2015). Participatory exhibition development is about inviting participants who are not museum staff to actively contribute to different phases of the exhibition process. It can be about generating ideas and themes, making selections of objects, arranging the exhibition space, or contributing to overall concepts or approaches (Davies, 2010). Such curatorial processes can also include community or visitor participation. However, it is also known that multidisciplinary teams can encounter difficulties when sharing and developing practice (Zahedi et al., 2017).

In this chapter, we will focus on the collaboration between two teams: museum professionals and university researchers. We will also use the concept of cultures of recognition to unfold some aspects of the collaborative design process (Kress \& Selander, 2012; Selander \& Kress, 2010) where the participants gradually reach an understanding of some target questions, transform their ideas over 
time, and realize them by different means (modes and media) in an exhibition. We hereby also wish to contribute theoretically to the education field, adapting and expanding on the notion of cultures of recognition to describe and interpret knowledge change in cross-institutional collaboration.

We describe how the collaboration between museum professionals and university researchers contributed new ideas for the development of an exhibition-by way of discussions about the goals, collaborative problem-solving, an ongoing iterative dialogue, and critical reflection. We will describe how the collaborative design project started, what the different teams chose to focus on, how ideas were introduced and recognized, and how representations of ideas were realized and transformed in workshops and further materialized in the new exhibition. The chapter concludes by discussing some of the possibilities identified and constraints for meaning-making that may be involved in a crossinstitutional collaborative design process between museum professionals and education researchers.

\section{The collaborative design project}

The collaborative design process started as a project between museum staff and education researchers when an older exhibition had been closed due to a planned reconstruction. The museum was about to change its exhibition on evolution by shifting the focus from how the earth (stones and minerals) developed during different periods of time to a focus on living organisms (plants and animals) before humankind evolved. During the collaborative design process, representations of evolution were negotiated and transformed into a new exhibition, and the modes and media were used in different ways to focus on different aspects of evolution.

In the process of re-designing the exhibition, a group of researchers from a university was invited by the curatorial team to take part in the design process. The curatorial team consisted of a project manager, an assistant project manager, two museum educators plus two consulting educators, four experts responsible for the academic content, an exhibit designer, a carpenter, two technicians, and a media producer. The research team consisted of four researchers in education who were asked to contribute with a design-oriented, multimodal perspective on knowledge representations, as well as contribute to the revision and "modernization" of the design of the exhibition.

The role of the researchers was that of critical friends who could act as a sounding board to the project team by providing feedback and asking questions that would prompt critical reflection (cf. Greenwood \& Levin, 2007; Selander, 2017). More specifically, the role of the researchers was (a) to introduce some themes from the Designs for Learning framework for the purpose of presenting basic concepts for collaborative reflection upon elements within the design process; (b) to discuss design in terms of the relations between text panels and labels, artefacts, and moving images during the shaping of the new exhibition; 
and (c) to discuss with the curatorial team how design could affect visitors' opportunities to engage with the new exhibition. From the very beginning of the collaboration, it was made clear that the material realization and actual re-design was the responsibility of the curatorial team-they were the content experts and exhibition experts. Overall, this seemed to be fruitful for both parties in relation to the interests of each of the teams.

The two teams - the curatorial team and the research team-collaborated in a series of conversations, meetings, and workshops over a period of three years. The two teams met at the museum a total of eight times. Data included photos from the various stages of exhibition work; photos from the old exhibition, from works in progress, including sketches and models, and photos from the new exhibition. During each meeting, the researchers took photographs, made field notes, and collected different types of documents from the project team: an exhibition synopsis, internal policy documents, as well as the steering document from the government. The target agreement stated that the new exhibition should include, for example, "digital text-carriers," "interactive exhibits that activate several senses," "content corresponding with new research findings," and "new reconstructions and objects that contribute to a narrative." The exhibition should also have "a trend-setting and timeless form."

\section{Cultures of recognition and esoteric and exoteric ideas}

According to Selander and Kress (2010) and Kress and Selander (2012), the term culture of recognition has to do with what is valued as relevant knowledge within a specific context. We could compare this term with how Fleck (1997) defined the social aspect of knowledge as something which is formed when two, or several, people exchange ideas on what is to be accepted as knowledge in a certain time and context. Such cultures are constructed as people make ideas and representations of knowledge visible within social organizations, something which results in stronger bonds. An organization also tends to create mutual affirmation and sometimes even intolerance of what may be perceived as new, foreign, or different. The organizations that are strictly delimited by regulations, rules, and guidelines help to maintain recognized ideas and knowledge- the cultures of knowledge. Cultures of recognition are likewise created and shaped through communication, recurring meetings, and collaboration between the people involved. Knowledge gains its recognition and legitimacy when members negotiate and repeat values within the specific organization.

Cultures of recognition can also be seen as effects of the use of social power, and in that way some actors (e.g., teachers) will have greater legacy and capacity to act and decide than others (e.g., pupils). Recognition can thus be linked to overall institutional social organizations, for example, relationships between and among individuals and social groups. Value systems, interests, norms, and 
rules of a particular social group form and transform the cultures of recognition and influence what counts as valuable knowledge.

What is then recognized as knowledge is developed and shaped over time in relation to collective ways of thinking and acting within these social groups or organizations. For example, museum professionals and education researchers usually belong to different social organizations with differing cultures of recognition. Cultures of recognition can nevertheless change and evolve if the organization is open and democratic. In such cases, the influence of esoteric and exoteric ideas (cf. Fleck, 1997) are crucial, as they may enable different ideas of recognition to affect one another and make possible changes in the culture. An exoteric idea (outward-facing) emerges from a culture that is less familiar with a knowledge domain. Members use everyday concepts, for example, instead of subject specific language and they often position themselves as novices. On the other hand, an esoteric idea (inward-facing) is recognized by its scientific value. People who address esoteric ideas have an initiated position towards the subject matter. They can easily recognize what is perceived as quality within the culture, and they use a precise language that either includes or excludes other perspectives on the subject knowledge.

Knowledge development takes place, as we see it, in the interplay between individuals, organizations, and cultures and in the traditions, norms and values that have developed around a specific knowledge domain. An individual may act more or less in relation to a certain culture of recognition. But this does not mean that the individual only acts on the basis of knowledge from one group and culture. Each individual can also take part in communication and collaboration within several different social organizations. One main difference between cultures of recognition is how they perceive the status of knowledge.

In the groups where esoteric ideas and actions occur, knowledge is often seen as more provisional or temporary and fallible. In these cultures, knowledge is recognized as time-bound, dynamic, and dependent on other facts. In cultures where exoteric ideas and actions dominate, perceptions about knowledge may be expressed in more secure and objectified ways. The relationship between these esoteric and exoteric ideas can be more or less open and reciprocal, more or less hierarchical. An open dialogical relationship allows influence from both sides, as an ongoing dialogue between different ideational positions. One can argue that if groups are open to the thoughts and ideas of others and allow themselves to recognize these ideas, the cultures of recognition might develop and change towards openness, democratic values, and advancement of knowledge. Nevertheless, this is far from being easy to achieve. Resistance or counter ideas are not easy to embrace, nor to work against. What is recognized as truth is affected by ideas from different cultures of recognition, but this does not mean that truth is something arbitrary or that all ideas can be treated equally. On the contrary, scientifically substantiated knowledge should not easily be rejected. At a time when science denial and conspiracy theories are widespread, it is important to distinguish knowledge from mere opinion. 
In the following, we will relate the reasoning about cultures of recognition to our empirical case. We will show how the two teams communicate their different perspectives regarding the exhibition, and how their perspectives and views of knowledge are influenced by esoteric and exoteric ideas in their respective cultures.

\section{Some central activities within the collaborative design process}

In retrospect, we can identify three central (core) activities, which formed the collaborative design process in the museum project: (a) initial orientation, (b) designing a series of workshops, and (c) mutual evaluation and critical reflection on practice and on moving theory forward.

\section{Initial orientation}

The collaborative design process began when the two teams, the curatorial team and the research team, met for the first time at the museum. The initial orientation was informal and gave the original team members the opportunity to get to know each other, and to identify some common ground of interests and issues to discuss. After establishing the first contact, more team members were recruited and became involved in the collaborative design process, together with the research team. Despite the fact that the groups had different knowledge interests, the meetings were characterized by mutual curiosity about each other's areas of knowledge. Each team and their participants came from different scientific disciplinary cultures, with different ideas of what counts as knowing. The two groups had differing interests and perceptions of core topics or agendas which related either to issues of developing practice or to issues of developing educational knowledge. There were also cultural differences internal to each of the teams, especially in the curatorial team which encompassed a wide variety of professionals ranging from experts responsible for content (such as a paleontologist) to the exhibit designer (with a strong background in art). However, the two teams came together to share the overarching goal of developing the exhibition; they also showed an interest in learning from each other.

The new exhibition needed to be re-framed by means of representation; these were both more attuned to current research and more in line with contemporary aesthetics. After the initial orientation, and at the very beginning of the collaboration, it became clear that the material realization and the actual re-design of the exhibition was an assignment for the curatorial team. It was they who were the experts in museum content and exhibition design; the role of the research group was to critically discuss certain takenfor-granted ideas, and to discuss how different design elements could be understood from the perspective of communication and education. Overall, this seemed to be a fruitful way of collaboration for both parties in relation 
to the interests of each of the teams. The researchers were asked to contribute with a theoretical understanding of Designs for Learning and a multimodal perspective on knowledge representations, as well as to contribute to the revision and "modernization" of the exhibition. In general, the museum professionals had a focus on epistemology, technology, and design, while the university researchers focused on interpretation and communication, as well as contributing to a reciprocal critical reflection upon certain representations in the old exhibition.

\section{Designing a series of workshops}

The two teams, the museum curatorial team and the university researcher team, met together several times over a period of three years, and collaborated in a series of workshops at the museum. Conducting a collaborative design process can be described as a social commitment, where the two professional teams gradually get to know each other and learn to develop successful means of communication. The first steps in this collaborative design process were informal, and the researchers' task was to receive information about the curatorial team's ways of doing things by asking questions. The researchers followed the curatorial team members around the museum; they re-visited the old exhibition and discussed questions concerning how the curatorial team perceived different objects or texts in the exhibition, and how they viewed different ways of solving the problems identified by the curatorial team. The researchers positioned themselves as friendly outsiders because of their limited knowledge of evolution. However, the focus was on the idea of working together and on challenging previous conventions so that divergent ideas, expectations, and new understandings of the task could emerge.

New questions and topics of conversation were continually developed from the frequent communication and collaboration between the two professional teams. In an early workshop the curatorial team outlined that the overall goal of the new exhibition was to change and adjust the design of the exhibition to address current conceptions of evolution and contemporary aesthetics. A new paradigmatic frame required new means of representation which were on the one hand more attuned to current research, and on the other more in line with contemporary aesthetics.

The curatorial team described the old exhibition as "outdated" by which they meant that it did not conform to contemporary theory. The old exhibition was based on a paradigmatic account of evolution in terms of chronology and development. The members of the curatorial team argued that this was evident in its overall focus as well as in the resources that dominated in its design. One example was the way fossils were arranged in the showcases. The fossils were placed next to each other without any context, only showing development from simple to more advanced species. A label explained how the evolution of species happens. 
In a dialogical discussion with the researchers, an exoteric idea which acknowledged the perspective of the visitor was recognized by the curatorial team. This was that the old paradigm was represented by a geological timeline in the exhibition design. The idea of development was also represented in the old exhibition through the display of fossils in dioramas, arranged in geological periods, such as Cretaceous, Jurassic, and Triassic. During the workshops, the university researchers continually asked critical questions about the layout, such as the arrangement of the displays of fossils. The research team, adopting more of an exoteric perspective (i.e., the audience and visitor's perspective), asked questions out of curiosity, and sometimes naïve questions, about the knowledge displayed in the different arrangements. Examples of the questions asked by the research team include:

- What story about evolution does the arrangement in this diorama represent?

- Why are these resources typically arranged in this way?

- What kind of knowledge is foregrounded/backgrounded?

- How are the resources used to design the story of change?

Different members of the curatorial team explained what they saw as some of the core problems with the old exhibition concerning how the story (narrative) of the evolution was represented. A new exhibition, the curatorial team argued, was going to be framed by a paradigmatic account of evolution in terms of ongoing change (rather than development), which should involve representations of evolution based upon processes whereby individual organisms' characteristics change from one form to another in successive generations. At the same time, the curatorial team saw that an overall message of the new exhibition was needed to illuminate that knowledge itself is something changeable, due to continual new research findings and paradigms in natural history research.

Evolution as we know it today steers organisms' abilities to reproduce. Organisms do not "strive" or "seek" to be perfectly adapted to their environment. Both the process of random events and natural selection in heredity control evolution. However, the concept of chronology was still considered a valid esoteric idea that the curatorial team argued should continue to be represented in the new exhibition. They did not approve of a thematic layout, even though this exoteric idea was discussed previously when the research team introduced it.

During one of the workshops and a re-visit to the old exhibition, the paradigmatic framing of development was recognized through the arrangements of material resources and objects from the museum collection. It was equally represented in detailed models in the dioramas, built environments with fabricated plants, colour-painted landscapes, and written labels. The curatorial team described the setting as dark and "spooky," which was something that they wanted to change. Geological periods and systems were also represented by 
colour-painted landscapes in dioramas. In addition, one person in the curatorial team outlined the ambition to re-conceptualize evolution by replacing the concept of development with the concept of change, but she still believed it was important to keep chronology as a crucial concept in representing evolution. The other team members agreed that evolution has no direction or goal. This recognition of another esoteric idea led to it being considered necessary to be realized in the exhibition.

The curatorial team members then argued that the concept of development should be replaced by that of change, as they considered evolution to be nonlinear and explained that "man is not the crowning achievement of creation." One question asked by the researcher team was "how can we then represent on-going change in the exhibition?" The curatorial team argued that one idea was to represent change, and particularly the extinction of species, as a blue light that would appear at certain points in a tunnel. However, later in the series of workshops, the curatorial team concluded that the extinction of species was not such an important aspect of evolution because extinction happens all the time. They further argued that evolution is the combination of many different factors, and the focus of the exhibition was to demonstrate its complexity and scope. The curatorial members decided, instead, to represent and name extinction using written text rather than lights or any other mode.

In another workshop at an early stage, the curatorial team wanted to install a globe, intended to show the movement of the continental plates, at the entrance of the exhibition. Such representations, they argued, would explain the origin of life and illuminate change from a paradigmatic frame. They also wanted a time-tunnel, so-called, to be placed directly after the entrance and the globe, which would represent the long journey through time up to the present day. In the time-tunnel the ceaseless flow of time would sometimes be interrupted and explained through important steps or new directions in evolution. It was also regarded as important to place the fossils, objects, and landscapes within a context framed by a contemporary account. A modern touch would be offered by resources such as aesthetic illumination, digital resources, and playing cards (similar to Pokémon cards but with fossils as a motif) on digital tablets. During the whole visit the visitor would thus be able to walk around and search for information displayed on a digital tablet.

The position of dinosaurs in the exhibition was also discussed within the collaborative design process. In the old exhibition, the dinosaurs were gathered together in groups in a larger area that would give the feeling of being in natural surroundings. However, the curatorial team considered it problematic that dinosaurs from different periods were placed together. This previous way of arranging dinosaurs and plants was considered unscientific, and therefore considered as an exoteric idea. It was also argued that the dinosaurs attracted too much attention, something considered to be problematic because visitors often went directly to these dinosaurs without paying any attention to the chronology. For the new exhibition, the idea was to form and arrange separate 
islands according to a new updated, and more scientifically correct, discourse of chronology. The curatorial team argued that this archipelago of islands would help the visitor to slow down and understand the chronology. On the islands, dinosaurs were placed together with fossils on podiums. The natural surrounding with plants and trees was removed, since these belonged to an older esoteric idea of how to display prehistory. A new esoteric idea had emerged in the curatorial team, which challenged exhibits that could not be supported scientifically.

An important story to tell, and something which all curatorial team members agreed upon, is that evolution continues. The re-designing of the exhibition was also going to be followed chronologically by yet another exhibition about the journey of humankind. The curatorial team wanted to link the two exhibitions to one another in order to show that our predecessors are traceable way back in time.

During discussions in the workshops, the researcher team challenged the curatorial team several times with knowledge-seeking questions. Such questions illustrated how imaginative visitors could perceive the knowledge about the relationships between these different time periods. The questions from the researchers pointed at exoteric ideas of evolution as constant change. In line with this, the curatorial team recognized these exoteric ideas, and decided to use footprints on the museum floor as representations of this continuum. A dinosaur footprint turned into a bird's footprint and a mammal footprint. The exhibition, they argued, needed an indistinct closure so as to represent continuity and constant change; something that led into the next exhibition.

\section{Evaluation and critical reflection on practice and on moving theory forward}

After the exhibition was designed and ready to be re-opened, the curatorial team invited the researchers to re-visit the museum and go through the new exhibition. An evaluation and critical reflection on practice took place through recognition of the different design elements that affected the outcome of the exhibition. During the tour, both teams recognized that the meaning of evolution was re-framed around the two concepts of change and chronology. The curatorial team argued that this was represented in three different ways: in dioramas, in a time-tunnel, and in an archipelago with islands.

The initial plan for the entrance to the new exhibition was to use a large hanging globe with digital "glowing" projection onto it. It would visualize change through the movement of continents, and emphasize that the history of life begins with this glowing globe. This focus on geology as a starting point for evolution was an important and often recurring esoteric idea expressed by some members of the curatorial team. Sometime later, this idea was challenged by another competing esoteric idea expressed by a member of the curatorial team. This member expressed the opinion that such a geological representation 
would give the wrong idea of what this exhibition was about; it was not about Earth and the movement of continents but about life. Stressing that the globe would represent something dead rather than alive, the member expressed that she wanted to see life growing. In the final version of the exhibition the suggested globe was removed. Instead, the entrance involved an open stand similar to an amphitheatre, and a panel with written text that named the exhibition and introduced its content about life on Earth and the changes that constitute evolution. The globe was replaced by images of extinct animals, for example, a flying dinosaur over water, framed by an introductory text.

After the entrance, visitors were invited to go through the time-tunnel that represented a long journey through time until the present. It had five sections and contained written text on panels, objects, as well as moving and still images. The representation of the time tunnel demonstrated important steps or new directions in evolution, such as the emergence of the skeleton and of predators, and the step and the transition of life from water to land. The esoteric idea of chronology and a continuing story thus became more accentuated through the different steps. For example, both chronology and change were represented by dinosaurs' footprints on the floor, which continued and morphed into bird and mammal footprints. The concept of change made it possible to produce knowledge about the extinction of species.

The meaning of evolution was also represented by resources such as dioramas, digital applications, and stationary tablets. The curatorial team was careful not to make materializations without scientific proofs. This change resulted in a modern representation, which focused more on aesthetics. Dinosaurs were now more scientifically correct compared to the old exhibition; islands and dioramas were arranged in a sequence following a suggested walking path. Fossils were also displayed differently, in a way that would demonstrate their value, almost like expensive jewellery displayed in a shop.

The aesthetic design was represented by conventional resources such as sound, colour, light, and the use of new digital resources which had an emotional impact in the new setting. The dark and naturalistic setting of the old exhibition, intended to create an atmosphere that appeared somewhat mysterious, was now gone. The re-designed exhibition, which was brighter and more modernistic, intended to move away from the previous ambience, and instead give value to the objects on display. During the final tour both teams recognized these changes of representation. In the new exhibition, the lighting was strongly focussed on floors and podiums, contributing a certain drama and vividness. As all podiums had different forms, the lighting created shadows and contrasts which were visual and visible to visitors. While the old exhibition contained rather few objects, the new exhibition included many objects in the form of fossils. The two teams discussed how objects had become more attractive to the audience. They were displayed to shine and sparkle like precious objects in a jewellery shop. Purple colour in the islands' showcases could be made to glitter by means of lighting. The curatorial team intended that the 
objects could be more highly valued, and the museum could teach the visitors to see what the museum appreciates and recognises as valuable knowledge. The team argued that by offering such a narrative, an aesthetic experience may be construed. An overarching message of the new exhibition was that knowledge is something changeable, due to the ongoing development of new research findings and paradigms in research. During the process of re-design, the different paradigmatic standpoints or ideas of chronology, development, and change became a meaningful challenge to be united in the exhibition.

\section{Conclusions}

In this final section, we will summarize our argument and draw some conclusions regarding the concept of cultures of recognition and how the museum professionals and university researchers made meaning and contributed to the collaborative design process. We will argue that the fusion of the different professional roles and expertise together framed and formed choices of esoteric and exoteric ideas for the development of the new exhibition.

The design-oriented framework presented by the university researchers and used in the workshops contributed new ideas to the exhibition development process. The esoteric ideas were considered by the curatorial team to be the most important knowledge in the narration of the new exhibition. These ideas differ from what can be included as important and significant knowledge from the perspective of other disciplinary areas. The esoteric ideas are often perceived as the core of the subject area, and they are often realized in representations of knowledge that are considered non-negotiable. So, what is recognized as an esoteric or an exoteric idea within a knowledge domain depends on the purpose of the area of use and the target group. In the analysis of the collaborative design process, the concept of cultures of recognition helped us discover some tensions between what was recognized within and across the professional groups. The exoteric ideas that university researchers expressed represented the visitor's perspective, and these ideas were also posed from a novice and an outsider perspective. These ideas represented knowledge that was considered less sacred. The esoteric ideas, on the other hand, were recognized by the curatorial team as conceptual requirements and valid scientific representations which foregrounded the overall account of the exhibition.

The scientific knowledge provided by the (differently skilled) museum professionals resulted in the need for negotiation as well as competition internally regarding the content and form of the exhibition. At the same time, as representatives of the museum they could make independent judgements and choices, and take stances that affected the outcome of the exhibition. On only one occasion was an esoteric idea (namely, the representation of geology in the globe) challenged by one of the curatorial team members who introduced an exoteric idea (representations of life) instead. The university researchers played a central role as critically reflective peers in the design process, and 
their collective body of knowledge afforded the museum professionals the means that became thinking devices, which also influenced the design process to a certain extent. This collaboration thus allowed scope for agency for the museum professionals.

In this chapter, we have shown how the concept of cultures of recognition is open to change through its relation to design. In this study, the participants had a mutual goal in the design of the exhibition, even though they were likely to have had different interests and understandings of the knowledge area and/ or subject matter. The participants' mutual interest in learning from each other meant that a change in ways of thinking was possible. Finally, the concept of culture of recognition helped us as researchers to recognize those views or ideas that were preferable in comparison to others.

\section{Acknowledgements}

We want to thank Staffan Selander and Tore West, who were participating researchers in this process.

\section{References}

Davies, S. M. (2010). The co-production of temporary museum exhibitions. Museum Management and Curatorship, 25(3), 305-321. https://doi.org/10.1080/09647775.2010. 498988

Fleck, L. (1997). Uppkomsten och utvecklingen av ett vetenskapligt faktum: Inledning till läran om tankestil och tankekollektiv [The genesis and development of a scientific fact: An introduction to the theory of thought style and thought collective]. Symposion.

Greenwood, D. J., \& Levin, M. (Eds.). (2007). Introduction to action research: Social research for social change. Sage Publications.

Kress, G., \& Selander, S. (2012). Multimodal design, learning and cultures of recognition. Internet and Higher Education, 15, 265-268.

McKenney, S., \& Reeves, T. (2019). Conducting educational design research. Routledge.

Mygind, L., Kahr Hällman, A., \& Bentsen, P. (2015). Bridging gaps between intentions and realities: A review of participatory exhibition development in museums. Museum Management and Curatorship, 30(2), 117-137. https://doi.org/10.1080/09647775.2015.1022903

Selander, S. (2017). Didaktiken efter Vygotskij-Design för lärande [Post-Vygotskian education: Designs for learning]. Liber.

Selander, S., \& Kress, G. (2010). Design för lärande—Ett multimodalt perspektiv [Designs for learning: A multimodal perspective]. Norstedts.

Van den Akker, J. (1999). Principles and methods of development research. In J. van den Akker, R. Branch, K. Gustafsson, N. Nieween, \& T. Plomp (Eds.), Design approaches and tools in education and training (pp. 1-14). Kluwer Academic Publishers.

Wang, F., \& Hannafin, M. (2005). Design-based research and technology-enhanced learning environments. Educational Technology Research and Development, 53(4), 5-23.

Zahedi, M., Tessier, V., \& Hawey, D. (2017). Understanding collaborative design through activity theory. The Design Journal, 20(sup1), S4611-S4620. https://doi.org/10.1080/14 606925.2017 .1352958 